\title{
Managing Innovation under Time Pressure: A Practical Perspective
}

\author{
Blair Winsor
}

\author{
(6) \\ He that will not apply new remedies must expect new evils, \\ for time is the greatest innovator. \\ Francis Bacon (1561-1626) \\ Philosopher, statesman, scientist, jurist, and author
}

\begin{abstract}
This article examines the effects of time pressure on innovation. Does time pressure stimulate or eliminate innovation or, in other words, should managers increase or reduce time pressures if they are trying to enhance innovation in their firms? Unfortunately, current research on the subject is ambivalent. To provide some clarity, this innovation management dilemma was examined in a fast-growing, medium-sized communication and IT consultancy ("First"), which claimed to be "highly innovative". Detailed data on five projects was collected over an 18-month period using practice-based methods. Each project team was followed in real time via observation and interviews. The data was then analyzed by dividing project work into three phases: i) negotiating the project particulars with the client; ii) conducting project work; and iii) project evaluation. This detailed analysis revealed how time pressures eliminated innovation in First's client-based project work and suggested three implications for the management of innovation. Firstly, managers should try to avoid imposing excessive time pressures on their project teams. Secondly, they should ensure that there is space between projects to enable reflection. Thirdly, managers should ensure that project debriefs occur and that they cover potential innovations.
\end{abstract}

\section{Introduction}

The effective management of innovation is an important topic for most businesses and will very likely become more important as the 21st century progresses (Tidd and Bessant, 2009; tinyurl.com/cje7lpf). This article examines the effects of time on innovation in consultancy project work and the implications of these effects for innovation management. In this context, innovation management can be defined as: creating $a$ process that enables the sharing of knowledge leading to improvements to existing business processes and/or services or the creation of new processes and/or services (Swan et al., 1999: tinyurl.com/cgy3gje; Van de Ven, 1986: http://tinyurl.com/bvkr978). Consultancies are, arguably, an appropriate place to examine innovation management, as they invariably claim to be innovative and innovation management is usually considered essential for firm survival (Alvesson, 2004: tinyurl.com/bpugarq; Heusinkveld et al., 2009: tinyurl.com/c6xl59s). In addition, time, embodied in project schedules, billable hours, and utilization rates is a "commoditized" (i.e., each time measurement has an equivalent monetary value - time really is money in a consultancy!) and predominant element in consultancy work. Unsurprisingly, the existing literature suggests that time pressures are the norm in consultancy work (e.g., Alvesson, 2004: tinyurl.com/bpugarq; Keegan and Turner, 2002: tinyurl.com/ccjjotu). A logical consequence of the commodification of time is the desire to compress it; as Adam (2003; tinyurl.com/cpsyll5) notes "when time is money, faster means better". Consultancy project work is, then, an ideal place to examine the role that time pressures play in promoting or constraining innovation.

Time and its implications for businesses and managers has been an enduring topic generally (e.g., Taylor, 1911: tinyurl.com/cmj5uaf; Oncken and Wass, 1974: tinyurl.com/ 2813cxh; Covey, 1994: tinyurl.com/bm554t5). Time pressures in consultancies or project work has also been dis- 


\section{Managing Innovation under Time Pressure: A Practical Perspective}

\section{Blair Winsor}

cussed in previous research (e.g., Gardner et al., 2008: tinyurl.com/cl7hdte; Gersick, 1988: tinyurl.com/btfum24 and 1989: tinyurl.com/c4f3kfc; Heusinkveld and Benders, 2003: tinyurl.com/cyu3mtg and 2005: tinyurl.com/c7hbh6b; Keegan and Turner, 2002: tinyurl.com/ccjotu). However, despite this substantial effort there is still considerable disagreement among researchers, some suggesting that time pressures can increase innovation while others argue the opposite. A likely reason for this ambivalence is that much of their work has been limited to post-project accounts and interviewees' retrospective sense making, which may have obscured what was actually occurring. Additionally, this previous research has tended to focus on internal non-client projects designed to produce new services rather than innovation during "normal" client work. By examining the details of normal clientcentred project work as it occurred, the research used here attempts to overcome these shortcomings. This article will, then, after briefly explaining the research methodology and the data, discuss the practical innovation management issues associated with the stifling effects of time on innovation.

\section{Research Site and Data}

"First" was established in 1993 and from 2000 to 2008 had successfully expanded from one office in Scotland to three other offices in Houston, London, and The Hague. Revenues in 2010 were in excess of $£ 7$ million ( $\$ 11$ million). First's work was organized around two main service lines: i) communication strategy development and integrated (usually internal) communications (e.g., marketing of the client firm's intranet to firm employees) and ii) e-learning (e.g., interactive computer or web-based training, multimedia, and face-to-face training around virtual team working). Supporting these service lines was, what was termed, a subsidiary design and new media for communications, learning, and promotion service. This research was conducted in the Scotland office, which had about 20 of the firm's 100 consultants. First's clients included some of the largest firms in the oil and gas industry as well as other large multinationals. First's considerable success was based upon, at least from the Directors' perspectives, its ability to innovate. First presented itself to potential clients as a leader in the delivery of bespoke services in its areas of expertise and was "driven by innovation". First's 2008 business plan listed eight "...key innovations that have driven firm growth..." in the areas of ITbased work design and communications, including, for example, virtual team working and remote collaboration, learning management systems and video streaming, and productivity coaching.
The research for this article utilized the relatively new and evolving practice-based approach. This approach is derived from pre-existing qualitative ethnographic methods, which are widely used and accepted (Denzin and Lincoln, 2000: tinyurl.com/bnokmpk and 2005: tinyurl .com/d4pcclq). Nicolini (2009; tinyurl.com/c8gd7j6) offers an in-depth account of what constitutes practice-based methods. The approach is distinctive for the attention that is paid to the "micro-level" or granular details of work practices. This is particularly relevant here, where the focus was on the practical, even mundane, reality of innovation management. I followed five projects - referred to herein as Tec, Video, Invoicing, Expense, and Software - over a period of 18 months in 2007 and 2008. Access to consultants and project documents was virtually unfettered. In addition, some client access was negotiated, enabling observation of client/consultant meetings and a client interview. Forty interviews were conducted with First's consultants and additional data was also collected during 37 days of observation. On these days, I was able to "hot desk" with the consultants and could, therefore, closely observe their practices and informally ask questions or seek clarification as they went about project work. Observations were documented as they occurred or shortly thereafter. Data analysis was inductive and comprised three interrelated parts. In the first part, the transcribed interviews, observational notes/reflections, and project/client documentation were coded in NVivo (tinyurl.com/6myasf), broadly around the practices that constituted project work. This part of the research was open-ended, exploratory, and iterative. In the second part, the analysis focused more on the impact of time on innovation management in each project. In the final part, in order to refine the analysis, project practices were grouped according to three clearly defined project phases: i) negotiating the project particulars with the client; ii) conducting project work; and iii) project evaluation. This provides the framing for the discussion which follows the project descriptions below.

First usually carry out 60 to 70 projects in the Scotland office each year. The five projects briefly mentioned here were described by those involved as "fairly typical" of their work (see Table 1 for a summary of each project). The Tec project required the creation of two 30minute e-learning training modules. In the Video project, First designed a communications campaign to increase employee usage of the client's videoconferencing facilities. The Awareness Campaign, as it was called, had a number of components, including; branding, poster and prompt card production, website development, intranet advertising, and training 


\section{Managing Innovation under Time Pressure: A Practical Perspective}

\section{Blair Winsor}

Table 1. Summary of project data and findings

\begin{tabular}{|c|c|c|c|c|c|}
\hline & \multicolumn{5}{|c|}{ Project } \\
\hline & Tec & Video & Invoicing & Expense & Software \\
\hline Duration & $08 / 07-12 / 07$ & $01 / 08-07 / 08$ & $06 / 08-10 / 08$ & $08 / 08-12 / 08$ & $08 / 08-03 / 09$ \\
\hline Kvalue & $£ 26,000$ & $£ 13,000$ & $£ 17,000$ & $£ 10,000$ & $£ 60,000$ \\
\hline Purpose & $\begin{array}{l}\text { Train client staff } \\
\text { to use software }\end{array}$ & $\begin{array}{l}\text { Comms. for } \\
\text { video- } \\
\text { conferencing }\end{array}$ & $\begin{array}{l}\text { Comms. for } \\
\text { intro. of } \\
\text { invoicing system }\end{array}$ & $\begin{array}{l}\text { Comms. for } \\
\text { intro. of online } \\
\text { expense process }\end{array}$ & $\begin{array}{l}\text { Increase software } \\
\text { usage }\end{array}$ \\
\hline $\begin{array}{l}\text { Main } \\
\text { Deliverables }\end{array}$ & $\begin{array}{l}\text { Two } 30 \mathrm{~min} . \\
\text { e-learning } \\
\text { modules }\end{array}$ & $\begin{array}{l}\text { Branding; } \\
\text { Comms (emails, } \\
\text { webpage, } \\
\text { Poster/Zap } \\
\text { stand); Training } \\
\text { (class-based) }\end{array}$ & $\begin{array}{l}\text { Branding; } \\
\text { Comms } \\
\text { (webpage, news } \\
\text { letter, Poster/ } \\
\text { Zap stand, desk } \\
\text { drop); Training } \\
\text { (class-based) }\end{array}$ & $\begin{array}{l}\text { Comms (emails, } \\
\text { webpage, } \\
\text { deskdrop); } \\
\text { Training (class- } \\
\text { based) }\end{array}$ & $\begin{array}{l}\text { Branding; } \\
\text { Comms } \\
\text { (webpage); Full } \\
\text { website }\end{array}$ \\
\hline $\begin{array}{l}\text { Time } \\
\text { Pressures }\end{array}$ & $\begin{array}{l}\text { Very high - } \\
\text { caused by delays } \\
\text { and overruns in } \\
\text { Phase } 1\end{array}$ & $\begin{array}{l}\text { High - caused by } \\
\text { "project creep" }\end{array}$ & $\begin{array}{l}\text { High - caused by } \\
\text { potential for } \\
\text { delays }\end{array}$ & $\begin{array}{l}\text { High - caused by } \\
\text { potential for } \\
\text { delays }\end{array}$ & $\begin{array}{l}\text { High - caused by } \\
\text { "short } \\
\text { timeframe" }\end{array}$ \\
\hline
\end{tabular}

sessions. The next project, Invoicing, involved communication and training related to the use of a new electronic invoicing system and was part of a series of so-called "e-systems" being implemented by the client. In the Expense project, First delivered communication and training around the introduction of a new electronic business expense form. This was another e-systems implementation for the same client as Invoicing. The Software project was fairly large and complex for First and involved internal marketing and communications to increase the usage of a third party's software by about 2500 of the client's employees.

\section{Discussion}

Analysis of First's projects highlighted that time pressures eliminated innovation during project work. In other words, the consultancy team provided a bespoke service to the client - after all, this is what they were hired to do - which would, usually, be seen as innovative by the client. For First, however, this was routine, not innovative. This was surprising given the innovation claims and undeniable success enjoyed by the firm. While innovation can come from a variety of sources, not "harvesting" innovation from client project work leaves, arguably, a significant gap. However, time's stifling effect on innovation during project work can be clearly seen by dividing it into three phases. The first phase of work in all projects entailed a negotiation between First and the client to determine project tasks and overall timeframe and costs. Typically it was First's Business Developer who would negotiate with the client and she, unlike the client, had a deep knowledge of the tasks involved and consequently greater sensitivity to the time required to actually accomplish those tasks. When considering time, she applied several temporal heuristics, including implicit assumptions that clients would provide timely information, obtain internal approvals, and respond with feedback around aspects of the design, etc. in a prompt manner during the project. Many of First's projects came from long-term repeat clients, so there was often extensive previous experience on which to base these assumptions. Additionally, she considered the consultant's expected future workloads, though it would be quite exceptional to refuse projects because of scheduling issues, as, once accepted, there was often the possibility to delay or reschedule their start. So the business developer had a well-developed 


\section{Managing Innovation under Time Pressure: A Practical Perspective}

\section{Blair Winsor}

and sophisticated appreciation of time and tasks which she applied during contract negotiations with the client. Clock time as it related to work tasks was, then, "fixed" in client contracts, which were in many instances very brief, focused on clock-time frames, day rates, delivery dates, and so forth, and this was where the emphasis would lie in the management of First's project work. This emphasis generated the initial circumstances that appeared to militate against providing First's workers with conditions conducive to innovation during the next phase.

The second phase of project work entailed the development of the service for the client. Schedules here were tightly overseen and consultants billing and utilization were regularly monitored in all projects. First's managers were deeply aware of the vicissitudes of the work, having previously worked as consultants themselves and, given First's medium size, their close proximity to the project work. However, this sensitivity, somewhat paradoxically reinforced their focus in this phase on the three overarching aspects of clock time that predominated here: project schedule, billing, and utilization. This kind of managerial oversight was focused on the short term, aiming to control and create orderly patterns of project work. This focus played a significant role in the work of project teams, arguably shaping their ability to engage in innovative practices. First's Business Developer and project managers had primary responsibility for ensuring that the clock-time goals related to billing and utilization were met. Using the firm's billing and utilization systems, they would continually track projects and individuals to ensure that stipulated times were being met. Clients were similarly focused on this commoditized time. They had limited budgets and needed to ensure, not only that services were delivered on time, but also that they were on budget. Both client and consultants were then, driven by the clichéd assertion that "time is money". The effect of this emphasis on time-based control in this phase was to inhibit innovation. First's consultants also had tight work schedules; almost invariably, they were juggling multiple projects at the same time or when they finished one project they were immediately starting another. Time pressures therefore, made the intervals between projects very short or non-existent. This lack of "slack" in consultants' work lives seemed, arguably, to affect their ability to reflect on their work and, therefore, severely limited their ability to think about innovation. It is in this phase, then, that the stifling effects of time pres- sures on innovation can best be seen. There was simply no time to think about innovation, the overriding imperative was to finish the project!

The third phase of project work entailed an evaluation of the project by the client, the project team, and First management. Given the importance placed on timeframes during project delivery they were, assuming that the agreed project services had been delivered, the most crucial component of this evaluation (Lindkvist et al., 1998; tinyurl.com/bvaofca). If project timeframes had been met, or shortened, then the project was judged a "success" and project team members quickly moved on to the next project. Additionally, First rarely conducted project debriefs or "washes" except where problems resulting in failure to meet budgets were encountered. Thus, even project evaluations seemed to limit potential innovation.

This analysis, then, suggests that managers working in project-based environments should be extremely wary of time's effects on innovation and guard against imposing excessive time pressures where innovation is needed, as time pressures here, rather than enhancing innovation, actually stifled it. Arguably, managers, need to do three things. Firstly, try to avoid imposing excessive time pressures on their workers, as these appear to be detrimental to innovation during project work. In other words, managers should realize that how they use time control will have an effect on innovation, particularly if they decide to focus on the use of time to control project work. A heightened awareness of the implications of time in project work may enable firms to increase their innovative output while still maintaining project control. Secondly, ensure that there is time between projects to enable workers to reflect on their practices. This slack or "down time" is, perhaps, particularly important where the project work is highly time pressured. Thirdly, ensure that project debriefs occur and that they cover potential innovations, for example, asking project team members to reflect on what could have been done differently. Overall, managers must be very conscious of the impact of time-based control systems on innovation. In First, many of these were not designed, if designed at all, to encourage innovation in project work. Indeed, First's management appeared to be unaware that their billing and utilization system did not have to be "taken for granted" and could be adjusted to enhance or stifle innovation. 


\section{Managing Innovation under Time Pressure: A Practical Perspective}

\section{Blair Winsor}

\section{Conclusion}

Innovation management and time were examined in a successful medium-sized consultancy. The analysis revealed that time pressures eliminated innovation in the consultancy's project work and suggested three implications for the management of innovation in time-pressured environments. So the message for 21 st century managers is clear: they need to be highly sensitive to the effects of time in their workplace to ensure that time enhances rather than stifles innovation.

\section{Acknowledgements}

This article is based on my recently completed $\mathrm{PhD}$ studies at Warwick Business School and I wish to acknowledge and thank Professor Jacky Swan and Professor Maxine Robertson for their exceptional scholarly support currently and during that process.

\section{About the Author}

Blair Winsor is a full-time lecturer in Edinburgh Napier University's business school in the United Kingdom and currently teaches in the innovation management and entrepreneurship areas. He received his $\mathrm{PhD}$ from the University of Warwick's Business School where he studied innovation in consultancies. Blair also has an MBA from SDA Bocconi in Italy and a law degree from the University of Ottawa in Canada. He has had business and consultancy experience in both the United Kingdom and North America.

Citation: Winsor, B. 2012. Managing Innovation under

Time Pressure: A Practical Perspective. Technology

(cc) BY 